\title{
Assessment of Key Success Factors for Industry 4.0 Implementation in Manufacturing Industry using EDAS
}

\author{
Rimalini Gadekar1, Bijan Sarkar², Ashish Gadekar ${ }^{3}$ \\ ${ }^{1}$ Mechanical Engineering Department, Government Polytechnic Gondia, India \\ ${ }^{2}$ Jadavpur University Kolkata, \\ ${ }^{3}$ Amity Institute of Higher Education Mauritius
}

Received on: 11 December, 2020, Revised on: 10 January, 2021, Published on: 16 January, 2021

\begin{abstract}
Industry 4.0 has become famous in the manufacturing sector because of its advantages, i.e., cost reduction, increased quality, higher performance, higher productivity, and high returns on investment. This urged policymakers and experts to imbibe Industry 4.0 in their day to day operations. This paper intends to analyze empirically the critical determining factors for implementing Industry 4.0 in the manufacturing company using Evaluation Based on Distance from Average Solution (EDAS) method. Initially, the researchers extracted 11 Key Success Factors (KSFs) and evaluated them based on 9 Performance Indicators (PIs). The priority ranking of these KSFs obtained through EDAS, will steer the way forward to manufacturing industries to introduce Industry 4.0. This research uses the insights from manufacturing industry experts to make the study viable and practically implementable. Internet infrastructure followed by Existing Technology Compliant with industry 4.0 is the key and deciding success factors in the overall implementation of Industry 4.0 framework. The low latency, seamless connectivity, and high reliability of internet infrastructure should be considered essential for successful implementation standards. The findings of the study would encourage manufacturing companies to devise plans and strategies for the effective implementation of Industry 4.0.
\end{abstract}

Keywords- Industry 4.0, Key Success Factor, MCDM, EDAS, Performance Indicator, Sustainability.

\section{I- INTRODUCTION}

T he term Industry 4.0 has been first manifested at Hanover fair Germany in the year 2011 [13],[25] is now known as the fourth industrial revolution globally. Many manufacturing firms are struggling to survive because of the dynamic landscape in the business world. Hence smart customers, product quality, agility, competitiveness are the main factors that need attention and considerations [9]. Smart customers, product quality, agility, competitiveness are the main factors that need to focus urgently [5]. Industry 4.0 is a progressive phase of preparation, execution, and management of the entire value chain of the product life cycle and focuses on personalized development based on consumer requirements [19]. Cyber-physical system (CPS.), Augmented reality, Virtual Reality (AR/VR), Big data analytics (BDA), Cloud computing (CC), Additive Manufacturing(AM), Internet of Things (IoT), Machine Learning, Cyber security, Simulation, embedded system etc. are the backbone of Industry 4.0. Industry 4.0 is associated with the strong integration of humans into the manufacturing processes to ensure quality improvement and focus on value-added activities and eliminating waste [45]. Indian manufacturing companies possess a lot of challenges, i.e., lack of knowledge about Industry 4.0, Scarcity of infrastructure, Insufficient training and lack of skills, Cyber security and data ownership concerns, lack of standards and governmental support, and so on [14],[35],[17],[22]. Effective implementation of Industry 4.0 depends on how well the key success 


\section{International Journal of Innovations in Engineering and Science, www.ijies.net}

factors for implementation are tackled [43]. This research is an attempt to assess the key success factors of Industry 4.0 in the manufacturing industry using Evaluation Based on Distance from Average Solution (EDAS) and prioritized these success factors. Attained priority ranking would enable industry 4.0 practitioners and policymakers to build a roadmap and devise a strategic plan for its implementation. The paper is divided into the following sections: section II elaborates Literature review. Section III describes the detailed Research Methodology used in this study. Analysis and results were discussed in section IV. Section V sheds light on Discussion and Managerial Implications, and at last, the Conclusion is deliberated in section VI.

\section{II-LITERATURE REVIEW}

A systematic literature review is the central pillar of any research work and provides a robust basis for developing quality research. The key success KSFs have been established through a comprehensive literature review and expert opinion on Industry 4.0 in the manufacturing industry. Managers and practitioners have recognized that there are several key success drivers for the introduction of Industry 4.0 innovations that need to be studied and evaluated to reap the benefits. The literature on KSFs for Industry 4.0 is found to be scarce. This raises concerns and needs to be addressed for the successful adoption of industry 4.0 developments in the Small and Medium scale industries (SMEs) [7], [28]. The study on the interrelationship among the enablers of Industry 4.0 to achieve sustainability through the Decision-Making Trial and Evaluation Laboratory (DEMATEL) approach [23] is just one of its kind. This study used Multi criteria decision-making methods (MCDM), i.e., Preference Ranking Organization Method for Enrichment of Evaluations (PROMETHEE), Technique for Order of Preference by Similarity to Ideal Solution (TOPSIS), Elimination Et Choix Traduisant la REalité (ELECTRE), Analytic Hierarchy Process (AHP) for prioritizing the factors affecting the readiness of manufacturing and service industries for the adoption of industry 4.0. The outcomes of these four approaches were compared for their effectiveness and the shortfalls applicable to the concerned issue [43]. The recent developments in Industry 4.0 adoption were discussed in European countries by collecting the input data through interviews with experts at Bulgarian local SMEs to understand the readiness and awareness towards the digitalized business model [29]. According to Harris et al., (2019) the willingness of small and medium-sized manufacturers (SMMs) to introduce digital infrastructure is a very significant success factor validated in an indepth interview with industry 4.0 professionals. A study conducted to assess the maturity of 20 Italian manufacturing companies using an analytical and multiple case study methodology indicates that the managers of these companies are very keen to identify effective strategies for the implementation of Industry 4.0 [33]. The primary goal of Industry 4.0 is to incorporate the technologies mainly CPS, IoT, CC, AI, BDA and AM to build a smart factory where CPS interacts with humans and machines lead to sustainable manufacturing processes [15],[24], [32], [34], [39]. The introduction of Industry 4.0 technology will alter the way people work [27],[41], rendering company's competitiveness as well. Resistance to change is one of the key challenges in the adoption of Industry 4.0 [8], so that leadership and top management play a very important role in coping with this [47]. Very little research has been noticed referring to the broader spectrum of key success factors for the deployment of industry 4.0. In this research, eleven KSFs and nine Performance Indicators (PIs) were identified for the study. Based on these PIs the KSFs were evaluated. The findings of this study will certainly add to the latest knowledge and enable managers and practitioners to build a roadmap for the implementation of Industry 4.0. The table 1 and 2 shows the KSFs and PIs considered for the study.

Table 1- Key Success Factors for Industry 4.0 implementation

\begin{tabular}{|l|l|l|l|}
\hline S N & Key Success Factors & Description & Reference \\
\hline 1 & $\begin{array}{l}\text { Managerial Support and } \\
\text { Leadership (KSF1) }\end{array}$ & $\begin{array}{l}\text { To align the organizational objective of implementing new } \\
\text { technology, top management commitment, and a supportive } \\
\text { attitude towards formulating strategies and action plan is essential. }\end{array}$ & {$[31],[40]$} \\
\hline 2 & $\begin{array}{l}\text { Internet Infrastructure } \\
\text { KSF2) }\end{array}$ & $\begin{array}{l}\text { The peripherals that contribute to the internet infrastructure are low } \\
\text { latency networks, servers, data storage and processing devices, } \\
\text { appropriate data transmission, and good communication protocols. }\end{array}$ & [42] \\
\hline
\end{tabular}


Vol. 6, No. 1, 2021, PP. 01-11

International Journal of Innovations in Engineering and Science, www.ijies.net

\begin{tabular}{|c|c|c|c|}
\hline 3 & Financial Support (KSF3) & $\begin{array}{l}\text { To attain new technical improvements in the organization, } \\
\text { sufficient financial support, and the allocation of funds to the } \\
\text { services needed must be adopted. }\end{array}$ & {$[31],[46]$} \\
\hline 4 & Data Security (KSF4) & $\begin{array}{l}\text { A lack of confidence in modern technology, insecure data sharing } \\
\text { and handling questioning its potential and worries about its future } \\
\text { unfavorable implications. }\end{array}$ & {$[34],[46]$} \\
\hline 5 & $\begin{array}{l}\text { Collaboration and } \\
\text { Teamwork (KSF5) }\end{array}$ & $\begin{array}{l}\text { Effective coordination, exchange of information, and cooperation } \\
\text { among members of the supply chain are very critical. }\end{array}$ & {$[2],[23]$} \\
\hline 6 & $\begin{array}{l}\text { Existing Workforce Skills } \\
\text { Compatibility (KSF6) }\end{array}$ & $\begin{array}{l}\text { Adequate compatibility with technical skills is expected for } \\
\text { existing employees to manage new technological infrastructure. }\end{array}$ & [29] \\
\hline 7 & $\begin{array}{l}\text { Competition and Pressure } \\
\text { from Business Partner } \\
(\text { KSF7) }\end{array}$ & $\begin{array}{l}\text { Competition and market pressure from business partners will force } \\
\text { companies to adopt creative technology implementation }\end{array}$ & {$[44]$} \\
\hline 8 & $\begin{array}{l}\text { Hardware and Software } \\
\text { Compatibility and } \\
\text { Availability (KSF8) }\end{array}$ & $\begin{array}{l}\text { High quality, compatibility, and availability of hardware and } \\
\text { software play a significant role within the enterprise in distributing } \\
\text { data and information. }\end{array}$ & {$[36]$} \\
\hline 9 & $\begin{array}{l}\text { Government and Legal } \\
\text { support (KSF9) }\end{array}$ & $\begin{array}{l}\text { Legislative rules, regulations and infrastructural assistance from } \\
\text { governments would help combat the challenges companies face on } \\
\text { the road to the adoption of Industry } 4.0 .\end{array}$ & {$[2]$} \\
\hline 10 & $\begin{array}{l}\text { Customer Expectations } \\
\text { (KSF10) }\end{array}$ & $\begin{array}{l}\text { To maintain good customer relations without scarifying service } \\
\text { and efficiency, companies must concentrate on customer } \\
\text { expectations. }\end{array}$ & {$[26],[44]$} \\
\hline 11 & $\begin{array}{l}\text { Existing Technology } \\
\text { Compliant with industry } 4.0 \\
(\text { KSF11) }\end{array}$ & $\begin{array}{l}\text { Sensors and actuators, IoT devices will make a significant } \\
\text { contribution to making existing technology compliant with } \\
\text { Industry 4.0. }\end{array}$ & {$[12]$} \\
\hline
\end{tabular}

Table 2- Performance Indicators for Industry 4.0 implementation

\begin{tabular}{|l|l|l|l|}
\hline S N & Performance Indicators & \multicolumn{1}{|c|}{ Description } & Reference \\
\hline 1 & Virtualization (PI1) & $\begin{array}{l}\text { This facilitates smooth inter-company operations that will provide } \\
\text { all participating organizations with real-time access to relevant } \\
\text { product and production details. }\end{array}$ & {$[4]$} \\
\hline 2 & Connectivity (PI2) & $\begin{array}{l}\text { Interconnectedness capability and data transmission levels } \\
\text { throughout networks, platforms, and applications. }\end{array}$ & {$[30]$} \\
\hline 3 & Interoperability (PI3) & $\begin{array}{l}\text { The capacity of systems to share, use the information, and use each } \\
\text { other's features. }\end{array}$ & {$[20],[37]$} \\
\hline 4 & Service orientation (PI4) & $\begin{array}{l}\text { To create products based on the customer 's specifications, people } \\
\text { and smart objects/devices must communicate effectively through } \\
\text { the Internet of Services. }\end{array}$ & {$[18],[40]$} \\
\hline 5 & IT. Infrastructure (PI5) & $\begin{array}{l}\text { Infrastructure capabilities to store and interpret massive quantities } \\
\text { of data. }\end{array}$ & {$[3]$} \\
\hline 6 & $\begin{array}{l}\text { Real-time Decision-Making } \\
\text { Capability (PI6) }\end{array}$ & $\begin{array}{l}\text { A smart factory needs to be able to gather, store, or evaluate real- } \\
\text { time information and make decisions. }\end{array}$ & {$[20]$, [21] } \\
\hline
\end{tabular}


International Journal of Innovations in Engineering and Science, www.ijies.net

\begin{tabular}{|l|l|l|l|}
\hline 7 & Modularity (PI7) & $\begin{array}{l}\text { Reduces device complexity and generates building blocks that are } \\
\text { reusable. Allows flexibility in terms of manufacturing capacity, } \\
\text { product selection. }\end{array}$ & [37], [42] \\
\hline 8 & $\begin{array}{l}\text { Connected devices } \\
\text { collaboration Potential (PI8) }\end{array}$ & $\begin{array}{l}\text { Capability of connected devices to self-measure, aware and } \\
\text { prediction potential. }\end{array}$ & {$[18],[40]$} \\
\hline 9 & Decentralization (PI9) & Systems must be able to execute decisions on their own. & {$[27]$} \\
\hline
\end{tabular}

\section{III-METHODOLOGY}

This section presents the research methodology adopted, and Figure 1 elaborates the systematic approach followed in this study.

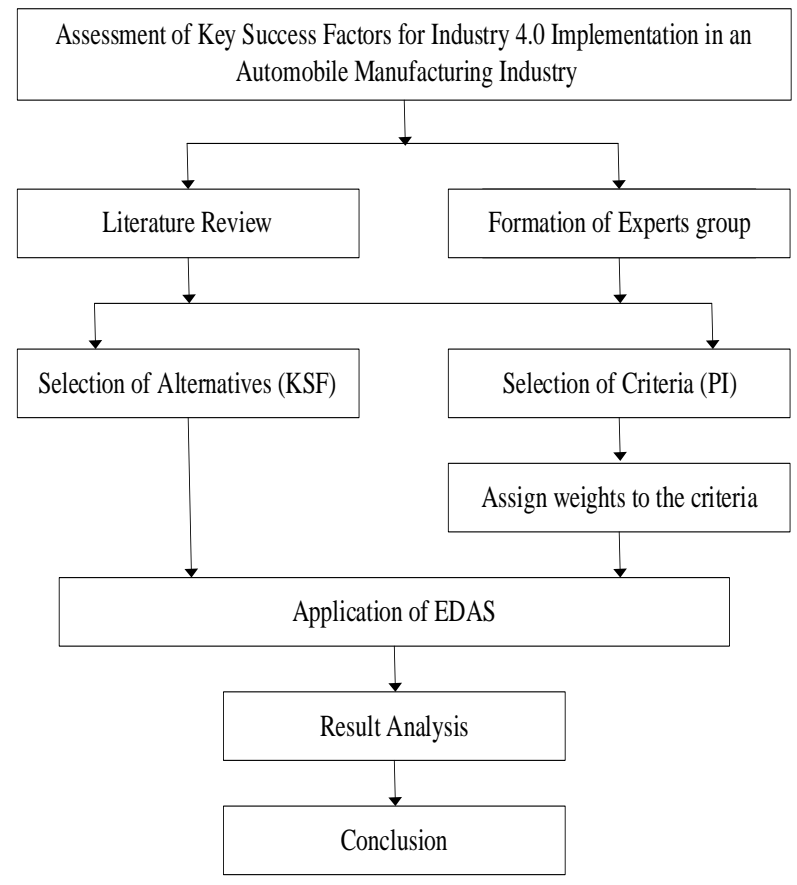

Fig 1- The Schematic representation of methodology for Assessment of Key Success Factors for Industry 4.0 Implementation in the Manufacturing Industry

A. Evaluation based on Distance from Average Solution (EDAS)

In EDAS best alternative selected based on the distance from the average solution was invented by Keshavarz Ghorabaee et al., 2015 [16], applied to the inventory classification problem. As outlined below, the steps to be followed using the EDAS method are,

Step 1: Select vital criteria and alternatives based on which the alternative should be rated.

Step 2: Develop the Decision Matrix (D) as shown below

$$
D=\left[D_{i j}\right]_{n x m}=\left[\begin{array}{cccc}
d_{11} & d_{12} & \ldots & d_{1 m} \\
d_{21} & d_{22} & \ldots & d_{2 m} \\
d_{31} & d_{32} & \ldots & d_{3 m} \\
\ldots & \ldots & \ldots & \ldots \\
d_{n 1} & d_{n 2} & \ldots & d_{n m}
\end{array}\right] \ldots(1)
$$

Where $D_{i j}$ implies the performance value of $\mathrm{i}^{\text {th }}$ alternative on $\mathrm{j}^{\text {th }}$ criteria.

Step 3: Evaluate the average solution by all criteria, as demonstrated below

$A V=\left[A V_{j}\right]_{1 \times m}$

Where,

$A V_{j}=\frac{\sum_{i=1}^{n} D_{i j}}{n}$

Step 4: Compute the positive distance from the average solution (PDA) and negative distance from the average solution (NDA) based on the type of the criteria, i.e., beneficial, and non-beneficial.

$$
\begin{aligned}
& P D A=\left[P D A_{i j}\right]_{n x m} \\
& N D A=\left[N D A_{i j}\right]_{n x m} .
\end{aligned}
$$

For $\mathrm{j}^{\text {th }}$ beneficial criteria

$$
\begin{aligned}
P D A_{i j} & =\frac{\max \left(0,\left(D_{i j}-A V_{j}\right)\right)}{A V_{j}} . \\
N D A_{i j} & =\frac{\max \left(0,\left(A V_{j}-D_{i j}\right)\right)}{A V_{j}} .
\end{aligned}
$$

For $\mathrm{j}^{\text {th }}$ non-beneficial criteria

$$
\begin{aligned}
P D A_{i j} & =\frac{\max \left(0,\left(A V_{j}-D_{i j}\right)\right)}{A V_{j}} \\
N D A_{i j} & =\frac{\max \left(0,\left(D_{i j}-A V_{j}\right)\right)}{A V_{j}}
\end{aligned}
$$




\section{International Journal of Innovations in Engineering and Science, www.ijies.net}

Where, $P D A_{i j}$ is the positive distance and $N D A_{i j}$ is the negative distance from the average solution in the sense of $\mathrm{i}^{\text {th }}$ alternative and $\mathrm{j}^{\text {th }}$ criteria.

Step 5: Calculate the weighted sum of PDA and NDA for all alternatives as below

$S P_{i}=\sum_{j=1}^{m} w_{j} P D A_{i j} \quad \ldots(10)$

$S N_{i}=\sum_{j=1}^{m} w_{j} N D A_{i j} \ldots$

Where, $w_{j}$ is the weight of $\mathrm{j}^{\text {th }}$ criteria

Step 6: Normalize the values of $S P$ and $S N$ for all alternatives using the following equation

$N S P_{i}=\frac{S P_{i}}{\max _{i}\left(S P_{i}\right)} \ldots$

$N S N_{i}=1-\frac{S N_{i}}{\max _{i}\left(S N_{i}\right)}$

Step 7: Calculate the Appraisal score $(A S)$ for all alternatives as below

$$
A S_{i}=\frac{1}{2}\left(N S P_{i}+N S N_{i}\right) \ldots(14)
$$

Where $0 \leq A S_{i} \leq 1$

Step 8: The alternative with the highest appraisal score selected as the best alternative.

A. Application of EDAS method for Assessment of Key Success Factors for Industry 4.0 Implementation in the Manufacturing Industry.

In this study, $11 \mathrm{KSF}$ of Industry 4.0 implementation have been evaluated on the basis of 9 PIs, listed in Tables 1 and 2. KSFs and PIs identified are finalized by a comprehensive literature review and verified by the experts of the six manufacturing industries (Step 1). These experts represent four manufacturing organizations in Maharashtra, India. They handled the projects related to Industry 4.0 and having expertise in Industry 4.0 practices, strategies, and pilot project development, possessing the experience of more than 15 years in production, supply chain management, product development, etc. in their respective companies.

EDAS method is used to rank these KSFs as per the steps mentioned in section II, A. The experts are being asked to rate the relationship between alternatives and criteria, i.e., KSFs and PIs as per the linguistic scale provided in Table 3 and assign the weights to the criteria selected for the study. The weights were assigned by the experts as per their subjective judgments as follows.

Virtualization (PI1): 0.05, Connectivity (PI2): 0.15, Interoperability (PI3): 0.15, Service Orientation (PI4):

0.1, IT infrastructure (P5):0.15, Real time Decision making capability (PI6):0.15, Modularity (PI7):0.05, Connected Device collaboration (PI8):0.1,

Decentralization (PI9):0.1

The 11x9 Initial Input matrix is formulated as per the opinion of experts in Table 4 (Step 1). The Decision Matrix is constructed by converting the linguistic scaled input given by the experts as per the rating, and the average solution for all the criteria is calculated given in Table 5 (Step 2 and Step 3). Further, PDA and NDA are calculated for beneficial and non-beneficial criteria shown in Tables 6 and 7 (Step 4). Here IT. Infrastructure is the non-beneficial criteria (PI5), and the rest of all criteria are the beneficial criteria. All the selected criteria having higher value, is better, but IT. infrastructure at a lower value is more desirable. The weighted sum of PDA and NDA computed is presented in Table 8 and 9 (Step 5). Normalized values of $S P$ and $S N$ and Appraisal score (AS) for all alternatives were calculated, as shown in Table 10 following (Step 6 and 7). Finally, from table 10 , by observing the ranking column, the alternative with higher AS is considered as the best alternative. From table 10, it is confirmed that alternative Internet Infrastructure (KSF2) is having the highest AS value i.e., 0.995878, among all other alternatives, which must be considered as a top priority for Industry 4.0 implementation.

Table 3-Linguistic Scale used for inputs taken from experts.

\begin{tabular}{|l|l|r|}
\hline Scale & Interpretation & \multicolumn{1}{|l|}{ Rating } \\
\hline EH & Extremely High & 1 \\
\hline VVH & Very Very High & 0.9 \\
\hline VH & Very High & 0.8 \\
\hline H & High & 0.7 \\
\hline MH & Medium-High & 0.6 \\
\hline M & Medium & 0.5 \\
\hline ML & Medium Low & 0.4 \\
\hline L & Low & 0.3 \\
\hline VL & Very Low & 0.2 \\
\hline VVL & Very Very Low & 0.1 \\
\hline
\end{tabular}


International Journal of Innovations in Engineering and Science, www.ijies.net

Table 4- Initial Input matrix

\begin{tabular}{|l|l|l|l|l|l|l|l|l|l|}
\hline KSF/PI & PI1 & PI2 & PI3 & PI4 & PI5 & PI6 & PI7 & PI8 & PI9 \\
\hline KSF1 & H & H & H & H & H & H & M & H & VH \\
\hline KSF2 & H & VVH & VH & VH & VH & VH & H & VH & E.H. \\
\hline KSF3 & VH & H & M & H & VVH & VH & H & VH & M \\
\hline KSF4 & VH & VVH & VH & VH & VVH & H & H & H & E.H. \\
\hline KSF5 & H & H & MH & H & VH & VH & VH & VH & VH \\
\hline KSF6 & M & MH & H & H & VH & H & H & H & H \\
\hline KSF7 & MH & M & H & H & H & MH & M & MH & MH \\
\hline KSF8 & VH & VVH & VH & H & VH & H & VH & VH & H \\
\hline KSF9 & MH & H & VH & VH & VVH & VH & H & VH & H \\
\hline KSF10 & VVH & VH & VH & VH & VH & H & H & VH & VH \\
\hline KSF11 & VH & VH & VVH & VH & VH & H & H & VH & VVH \\
\hline
\end{tabular}

Table 5- Decision matrix

\begin{tabular}{|l|l|l|l|l|l|l|l|l|l|}
\hline KSF/PI & PI1 & PI2 & PI3 & PI4 & PI5 & PI6 & PI7 & PI8 & PI9 \\
\hline KSF1 & 0.7 & 0.7 & 0.7 & 0.7 & 0.7 & 0.7 & 0.5 & 0.7 & 0.8 \\
\hline KSF2 & 0.7 & 0.9 & 0.8 & 0.8 & 0.8 & 0.8 & 0.7 & 0.8 & 1 \\
\hline KSF3 & 0.8 & 0.7 & 0.5 & 0.7 & 0.9 & 0.8 & 0.7 & 0.8 & 0.5 \\
\hline KSF4 & 0.8 & 0.9 & 0.8 & 0.8 & 0.9 & 0.7 & 0.7 & 0.7 & 1 \\
\hline KSF5 & 0.7 & 0.7 & 0.6 & 0.7 & 0.8 & 0.8 & 0.8 & 0.8 & 0.8 \\
\hline KSF6 & 0.5 & 0.6 & 0.7 & 0.7 & 0.8 & 0.7 & 0.7 & 0.7 & 0.7 \\
\hline KSF7 & 0.6 & 0.5 & 0.7 & 0.7 & 0.7 & 0.6 & 0.5 & 0.6 & 0.6 \\
\hline KSF8 & 0.8 & 0.9 & 0.8 & 0.7 & 0.8 & 0.7 & 0.8 & 0.8 & 0.7 \\
\hline KSF9 & 0.6 & 0.7 & 0.8 & 0.8 & 0.9 & 0.8 & 0.7 & 0.8 & 0.7 \\
\hline KSF10 & 0.9 & 0.8 & 0.8 & 0.8 & 0.8 & 0.7 & 0.7 & 0.8 & 0.8 \\
\hline KSF11 & 0.8 & 0.8 & 0.9 & 0.8 & 0.8 & 0.7 & 0.7 & 0.8 & 0.9 \\
\hline AV & 0.71818 & 0.74545 & 0.73636 & 0.74545 & 0.809091 & 0.727273 & 0.681818 & 0.754545 & 0.772727 \\
\hline
\end{tabular}

Table 6- Positive Distance from Average (PDA)

\begin{tabular}{|l|l|l|l|l|l|l|l|l|l|}
\hline Weights & 0.05 & 0.15 & 0.15 & 0.1 & 0.15 & 0.15 & 0.05 & 0.1 & 0.1 \\
\hline KSF/PI & PI1 & PI2 & PI3 & PI4 & PI5 & PI6 & PI7 & PI8 & PI9 \\
\hline KSF1 & 0 & 0 & 0 & 0 & 0.134831 & 0 & 0 & 0 & 0.035294 \\
\hline KSF2 & 0 & 0.207317 & 0.08642 & 0.073171 & 0.011236 & 0.1 & 0.026667 & 0.060241 & 0.294118 \\
\hline KSF3 & 0.113924 & 0 & 0 & 0 & 0 & 0.1 & 0.026667 & 0.060241 & 0 \\
\hline KSF4 & 0.113924 & 0.207317 & 0.08642 & 0.073171 & 0 & 0 & 0.026667 & 0 & 0.294118 \\
\hline KSF5 & 0 & 0 & 0 & 0 & 0.011236 & 0.1 & 0.173333 & 0.060241 & 0.035294 \\
\hline KSF6 & 0 & 0 & 0 & 0 & 0.011236 & 0 & 0.026667 & 0 & 0 \\
\hline KSF7 & 0 & 0 & 0 & 0 & 0.134831 & 0 & 0 & 0 & 0 \\
\hline KSF8 & 0.113924 & 0.207317 & 0.08642 & 0 & 0.011236 & 0 & 0.173333 & 0.060241 & 0 \\
\hline KSF9 & 0 & 0 & 0.08642 & 0.073171 & 0 & 0.1 & 0.026667 & 0.060241 & 0 \\
\hline KSF10 & 0.253165 & 0.073171 & 0.08642 & 0.073171 & 0.011236 & 0 & 0.026667 & 0.060241 & 0.035294 \\
\hline KSF11 & 0.113924 & 0.073171 & 0.222222 & 0.073171 & 0.011236 & 0 & 0.026667 & 0.060241 & 0.164706 \\
\hline
\end{tabular}


International Journal of Innovations in Engineering and Science, www.ijies.net

Table 7- Negative Distance from Average (NDA)

\begin{tabular}{|l|r|r|r|r|r|r|r|r|r|r|}
\hline Weights & 0.05 & 0.15 & 0.15 & 0.1 & 0.15 & 0.15 & 0.05 & 0.1 & 0.1 \\
\hline KSF/PI & PI1 & PI2 & PI3 & PI4 & PI5 & PI6 & PI7 & PI8 & PI9 \\
\hline KSF1 & 0.025316 & 0.060976 & 0.049383 & 0.060976 & 0 & 0.0375 & 0.266667 & 0.072289 & 0 \\
\hline KSF2 & 0.025316 & 0 & 0 & 0 & 0 & 0 & 0 & 0 & 0 \\
\hline KSF3 & 0 & 0.060976 & 0.320988 & 0.060976 & 0.11236 & 0 & 0 & 0 & 0.352941 \\
\hline KSF4 & 0 & 0 & 0 & 0 & 0.11236 & 0.0375 & 0 & 0.072289 & 0 \\
\hline KSF5 & 0.025316 & 0.060976 & 0.185185 & 0.060976 & 0 & 0 & 0 & 0 & 0 \\
\hline KSF6 & 0.303797 & 0.195122 & 0.049383 & 0.060976 & 0 & 0.0375 & 0 & 0.072289 & 0.094118 \\
\hline KSF7 & 0.164557 & 0.329268 & 0.049383 & 0.060976 & 0 & 0.175 & 0.266667 & 0.204819 & 0.223529 \\
\hline KSF8 & 0 & 0 & 0 & 0.060976 & 0 & 0.0375 & 0 & 0 & 0.094118 \\
\hline KSF9 & 0.164557 & 0.060976 & 0 & 0 & 0.11236 & 0 & 0 & 0 & 0.094118 \\
\hline KSF10 & 0 & 0 & 0 & 0 & 0 & 0.0375 & 0 & 0 & 0 \\
\hline KSF11 & 0 & 0 & 0 & 0 & 0 & 0.0375 & 0 & 0 & 0 \\
\hline
\end{tabular}

Table 8- Weighted Sum of PDA

\begin{tabular}{|l|r|r|r|r|r|r|r|r|r|l|}
\hline KSF/PI & PI1 & PI2 & PI3 & PI4 & PI5 & PI6 & PI7 & PI8 & II9 & SPi \\
\hline KSF1 & 0 & 0 & 0 & 0 & 0.020225 & 0 & 0 & 0 & 0.003529 & 0.023754 \\
\hline KSF2 & 0 & 0.031098 & 0.012963 & 0.007317 & 0.001685 & 0.015 & 0.001333 & 0.006024 & 0.029412 & 0.104832 \\
\hline KSF3 & 0.005696 & 0 & 0 & 0 & 0 & 0.015 & 0.001333 & 0.006024 & 0 & 0.028054 \\
\hline KSF4 & 0.005696 & 0.031098 & 0.012963 & 0.007317 & 0 & 0 & 0.001333 & 0 & 0.029412 & 0.087819 \\
\hline KSF5 & 0 & 0 & 0 & 0 & 0.001685 & 0.015 & 0.008667 & 0.006024 & 0.003529 & 0.034906 \\
\hline KSF6 & 0 & 0 & 0 & 0 & 0.001685 & 0 & 0.001333 & 0 & 0 & 0.003019 \\
\hline KSF7 & 0 & 0 & 0 & 0 & 0.020225 & 0 & 0 & 0 & 0 & 0.020225 \\
\hline KSF8 & 0.005696 & 0.031098 & 0.012963 & 0 & 0.001685 & 0 & 0.008667 & 0.006024 & 0 & 0.066133 \\
\hline KSF9 & 0 & 0 & 0.012963 & 0.007317 & 0 & 0.015 & 0.001333 & 0.006024 & 0 & 0.042637 \\
\hline KSF10 & 0.012658 & 0.010976 & 0.012963 & 0.007317 & 0.001685 & 0 & 0.001333 & 0.006024 & 0.003529 & 0.056486 \\
\hline KSF11 & 0.005696 & 0.010976 & 0.033333 & 0.007317 & 0.001685 & 0 & 0.001333 & 0.006024 & 0.016471 & 0.082836 \\
\hline
\end{tabular}

Table 9- Weighted sum of NDA

\begin{tabular}{|l|r|r|r|r|r|r|r|r|r|}
\hline KSF/PI & PI1 & PI2 & PI3 & PI4 & PI5 & PI6 & PI7 & PI8 & PI9 \\
\hline KSF1 & 0.001266 & 0.009146 & 0.007407 & 0.006098 & 0 & 0.005625 & 0.013333 & 0.007229 & 0 \\
\hline KSF2 & 0.001266 & 0 & 0 & 0 & 0 & 0 & 0 & 0 & 0 \\
\hline KSF3 & 0 & 0.009146 & 0.048148 & 0.006098 & 0.016854 & 0 & 0 & 0 & 0.035294 \\
\hline KSF4 & 0 & 0 & 0 & 0 & 0.016854 & 0.005625 & 0 & 0.007229 & 0 \\
\hline KSF5 & 0.001266 & 0.009146 & 0.027778 & 0.006098 & 0 & 0 & 0 & 0 & 0 \\
\hline KSF6 & 0.01519 & 0.029268 & 0.007407 & 0.006098 & 0 & 0.005625 & 0 & 0.007229 & 0.009412 \\
\hline KSF7 & 0.008228 & 0.04939 & 0.007407 & 0.006098 & 0 & 0.02625 & 0.013333 & 0.020482 & 0.022353 \\
\hline KSF8 & 0 & 0 & 0 & 0.006098 & 0 & 0.005625 & 0 & 0 & 0.009412 \\
\hline KSF9 & 0.008228 & 0.009146 & 0 & 0 & 0.016854 & 0 & 0 & 0 & 0.009412 \\
\hline KSF10 & 0 & 0 & 0 & 0 & 0 & 0.005625 & 0 & 0 & 0 \\
\hline KSF11 & 0 & 0 & 0 & 0 & 0 & 0.005625 & 0 & 0 & 0 \\
\hline
\end{tabular}


International Journal of Innovations in Engineering and Science, www.ijies.net

Table 10-Ranking of the alternatives

\begin{tabular}{|l|r|r|r|r|r|r|}
\hline & \multicolumn{1}{l|}{ SPi } & \multicolumn{1}{l|}{ SNi } & \multicolumn{1}{l|}{ NSPi } & \multicolumn{1}{l|}{ NSNi } & \multicolumn{1}{l|}{ ASi } & Rank \\
\hline KSF1 & 0.023754 & 0.050104 & 0.226592 & 0.673675 & 0.450133 & 8 \\
\hline KSF2 & 0.104832 & 0.001266 & 1 & 0.991756 & 0.995878 & 1 \\
\hline KSF3 & 0.028054 & 0.11554 & 0.267605 & 0.247498 & 0.257552 & 9 \\
\hline KSF4 & 0.087819 & 0.029708 & 0.837709 & 0.806516 & 0.822112 & 3 \\
\hline KSF5 & 0.034906 & 0.044288 & 0.332966 & 0.71156 & 0.522263 & 7 \\
\hline KSF6 & 0.003019 & 0.080229 & 0.028796 & 0.477477 & 0.253136 & 10 \\
\hline KSF7 & 0.020225 & 0.153541 & 0.192925 & 0 & 0.096462 & 11 \\
\hline KSF8 & 0.066133 & 0.021134 & 0.630845 & 0.862354 & 0.7466 & 5 \\
\hline KSF9 & 0.042637 & 0.04364 & 0.406721 & 0.715777 & 0.561249 & 6 \\
\hline KSF10 & 0.056486 & 0.005625 & 0.538824 & 0.963365 & 0.751095 & 4 \\
\hline KSF11 & 0.082836 & 0.005625 & 0.790174 & 0.963365 & 0.876769 & 2 \\
\hline
\end{tabular}

\section{IV-ANALYSIS AND RESULTS}

It is evident from Table 10 that KSF2 $>\mathrm{KSF} 11>\mathrm{KSF} 4$ $>\mathrm{KSF} 10>\mathrm{KSF} 8>\mathrm{KSF} 8>\mathrm{KSF} 9>\mathrm{KSF} 5>\mathrm{KSF} 1>$ $\mathrm{KSF} 3>\mathrm{KSF} 6>\mathrm{KSF} 7$ is the priority sequence of the KSFs for Industry 4.0 Implementation in the Manufacturing Industry obtained using the EDAS process. It depicts that the internet Infrastructure (KSF2) is the required prerequisite for industry 4.0 to achieve the goal of smart factory targets because all the components, i.e., human, machine and devices are interacted with each other and exchanges information to take the real-time decision. This is possible only with low latency, high bandwidth, and powerful internet infrastructure deployment. Our finding supports this most prominently, followed by the Existing technology compliant with industry 4.0 (KSF11). This is clear that every business would look forward to updating existing technological resources before implementing or buying new technological infrastructure. If the existing technological resources are compatible with upgrading, the way forward on the road of implementation of Industry 4.0 becomes simpler and more convenient for the businesses. Similarly, Data Security (KSF4), Customer expectations (KSF10), Hardware and Software Compatibility and Availability (KSF8) along with Government and legal support (KSF9), Collaboration and Teamwork (KSF5), Managerial Support and leadership (KSF1), Financial Support (KSF3), Existing Workforce Skills Compatibility (KSF6) are most crucial and needs attention as per their priority obtained, while deciding the plans and strategies for Industry 4.0 implementation. The study reveals that Competition and pressure from the business partner (KSF7) is less significant relative to others. If all the above-mentioned KSFs are taken care of properly, the KSF7 would automatically take care of itself.

\section{V- DISCUSSION AND MANAGERIAL IMPLICATIONS}

The study findings indicate that the most necessary and significant condition for the implementation of Industry 4.0 is the Internet infrastructure, which is close to the conclusions from Luthra et al., 2020. Installing the robust industrial internet and integrating it with machines and devices allows products to interact and communicate with machines. CPS promotes the collaboration initiative within machine products and humans [1],[10]. For this, managers should concentrate more on the appropriate industrial internet installations, CC, CPS, IoT, sensors, so that integrating digital services in the products will certainly increase product efficiency [6].

To decide on budget preparation for potential investments, the agility of current technologies, and their compatibility with the requirements of Industry 4.0 should be properly analyzed. Managers should come up with a substantial and realistic plan to understand the needs of the organization and the availability of resources. Thus, the organizations keen to imbibe Industry 4.0 should also concentrate on the responsiveness of managers, team leaders, employees, and policymakers to the effective development of the action plans for Data Security strategies, Customer Expectations, Collaboration, and Teamwork. Government and legal support are very critical, and the government should provide sustainable standards, laws, and regulations in order to create trust among stakeholders to drive valiantly on the road of implementation of Industry 4.0. This research is unique and holistically attempted to build a model to direct stakeholders to move step by step forward in Industry 4.0. journey. 


\section{International Journal of Innovations in Engineering and Science, www.ijies.net}

\section{VI-CONCLUSION}

The study has developed a model to rank the most significant KSFs responsible for the implementation of Industry 4.0 using the EDAS method. The in-depth literature review and six expert opinions from the manufacturing industries of Maharashtra, India were considered to finalize and validate the $11 \mathrm{KSF}$ and 9 PIs for the study. The outcome of the study revealed that the internet infrastructure is the most critical component of Industry 4.0 implementation decision making process and should be urgently attended as it has attained the highest rank in findings. This study makes the several contributions to the literature by developing the model for KSFs assessment for successful industry 4.0 implementation. The study has also contributed to the new insights and will enable managers, academicians, researchers, and policymakers to build their roadmap for the implementation of Industry 4.0. The findings are useful for all those manufacturing companies planning to adopt Industry 4.0 soon to formulate their strategic framework accordingly.

There are also some limitations to this research. In the background of Indian manufacturing industries, this research has been carried out to expand the perspective of Industry 4.0. The same study could be taken for other countries and sectors to obtain further insights into Industry 4.0. Here $11 \mathrm{KSF}$ and 9 PIs were finalized for the study. More exploration of KSFs and PIs would extract other dimensions of industry 4.0. EDAS. method was used for ranking the KSFs. The application of different MCDM techniques can be used to validate the obtained result. The analysis is focused on the judgments of the experts, their biases can impact the outcome of the study as the opinion can vary from person to person.

\section{REFERENCES}

[1] Babiceanu, R.F. and Seker, R., 2016. Big Data and virtualization for manufacturing cyberphysical systems: A survey of the current status and future outlook. Computers in Industry, 81, pp.128-137.

[2] Bag, S., Telukdarie, A., Pretorius, J.H.C. and Gupta, S., 2018. Industry 4.0 and supply chain sustainability: framework and future research directions. Benchmarking: An International Journal.

[3] Blatz, F., Bulander, R. and Dietel, M., 2018, June. Maturity model of digitization for S.M.E.s. In 2018 IEEE International Conference on Engineering, Technology and Innovation (ICE/ITMC) (pp. 1-9). IEEE.

[4] Brettel M, Friederichsen N, Keller M, Rosenberg M. How virtualization, decentralization and network building change the manufacturing landscape: An Industry 4.0 Perspective. International journal of mechanical, industrial science and engineering. 2014 Jan;8(1):37-44.

[5] R. Brousell, J. R. Moad, and P. Tate, "The next industrial revolution: How the internet of things and embedded, connected, Intelligent devices

[6] Dalenogare, L.S., Benitez, G.B., Ayala, N.F. and Frank, A.G., 2018. The expected contribution of Industry 4.0 technologies for industrial performance. International Journal of Production Economics, 204, pp.383-394.

[7] Dassisti, M., Panetto, H., Lezoche, M., Merla, P., Semeraro, C., Giovannini, A. and Chimienti, M., 2017, March. Industry 4.0 paradigm: The viewpoint of the small and medium enterprises.

[8] de Sousa Jabbour, A.B.L., Jabbour, C.J.C., Foropon, C. and Godinho Filho, M., 2018. When titans meet-Can industry 4.0 revolutionise the environmentally-sustainable manufacturing wave? The role of critical success factors. Technological Forecasting and Social Change, 132, pp.18-25.

[9] Frank, A.G., Dalenogare, L.S. and Ayala, N.F. (2019), "Industry 4.0 technologies: implementation

[10] Harris, G., Yarbrough, A., Abernathy, D. and Peters, C., 2019. Manufacturing Readiness for Digital Manufacturing. Manufacturing Letters, 22, pp.16-18.

[11] Hwang, C.L. and Yoon, K., 1981. Methods for multiple attribute decision making. In Multiple attribute decision making (pp. 58-191). Springer, Berlin, Heidelberg.

[12] Jazdi, N., 2014, May. Cyber physical systems in the context of Industry 4.0. In 2014 IEEE international conference on automation, quality and testing, robotics (pp. 1-4). IEEE.

[13] Kagermann, Acatech Report 2013 Accessed on 15 October 2020 available at https://www.din.de/blob/76902/e8cac883f42bf285 $36 \mathrm{e} 7 \mathrm{e} 8165993 \mathrm{f} 1 \mathrm{fd} / \mathrm{recommendations-for-}$ implementing-industry-4-0-data.pdf

[14] Kamble, S.S., Gunasekaran, A. and Sharma, R., 2018. Analysis of the driving and dependence power of barriers to adopt industry 4.0 in Indian manufacturing industry. Computers in Industry, 101, pp.107-119.

[15] Karadayi-Usta, S., 2019. An interpretive structural analysis for industry 4.0 adoption challenges. IEEE Transactions on Engineering Management.

[16] Keshavarz Ghorabaee, M., Zavadskas, E.K., Olfat, L. and Turskis, Z., 2015. Multi-criteria inventory classification using a new method of Evaluation based on distance from average solution (E.D.A.S.). Informatica, 26(3), pp.435451.

[17] Kovaite, K., Šūmakaris, P., Stankevičienè, J. and Korsakienė, R., 2019. Industry 4.0 as the Driving 


\section{International Journal of Innovations in Engineering and Science, www.ijies.net}

Force of S.M.E. Internationalisation: A Case of Lithuania. Economics and Business, 33(1), pp.192-206.

[18] Kozák, Š., Ružický, E., Štefanovič, J. and Schindler, F., 2018, February. Research and education for industry 4.0: Present development. In 2018 Cybernetics \& Informatics (K\&I) (pp. 18). IEEE.

[19] Lasi, H., Fettke, P., Kemper, H.G., Feld, T. and Hoffmann, M., 2014. Industry 4.0. Business \& information systems engineering,6(4), pp.239242.

[20] Lu, Y., 2017. Industry 4.0: A survey on technologies, applications and open research issues. Journal of industrial information integration, 6, pp.1-10.

[21] Lee, J., Jun, S., Chang, T.W. and Park, J., 2017. A smartness assessment framework for smart factories using analytic network process. Sustainability, 9(5), p.794.

[22] Ludwig, T., Kotthaus, C., Stein, M., Pipek, V. and Wulf, V., 2018. Revive old discussions! Sociotechnical challenges for small and medium enterprises within industry 4.0. In Proceedings of 16th European Conference on ComputerSupported Cooperative Work-Exploratory Papers. European Society for Socially Embedded Technologies (E.U.S.S.E.T.).

[23] Luthra, S., Kumar, A., Zavadskas, E.K., Mangla, S.K. and Garza-Reyes, J.A., 2020. Industry 4.0 as an enabler of sustainability diffusion in supply chain: an analysis of influential strength of drivers in an emerging economy. International Journal of Production Research, 58(5), pp.1505-1521.

[24] Manesh, M.F., Pellegrini, M.M., Marzi, G. and Dabic, M., 2020. Knowledge management in the fourth industrial revolution: Mapping the literature and scoping future avenues. IEEE Transactions on Engineering Management.

[25] Marnewick, C. and Marnewick, A.L., 2019. The demands of industry 4.0 on project teams. IEEE Transactions on Engineering Management.

[26] Mittal, S., Khan, M.A., Romero, D. and Wuest, T., 2018. A critical review of smart manufacturing \& Industry 4.0 maturity models: Implications for small and medium-sized enterprises (S.M.E.s). Journal of manufacturing systems, 49 , pp.194-214.

[27] Moktadir, M.A., Ali, S.M., Kusi-Sarpong, S. and Shaikh, M.A.A., 2018. Assessing challenges for implementing I4.0: Implications for process safety and environmental protection. Process Safety and Environmental Protection, 117, pp.730-741.

[28] Moeuf, A., Lamouri, S., Pellerin, R., TamayoGiraldo, S., Tobon-Valencia, E. and Eburdy, R., 2020. Identification of critical success factors, risks and opportunities of Industry 4.0 in S.M.E.s. International Journal of Production Research, 58(5), pp.1384-1400.
[29] Moraliyska, M. and Antonova, A., 2018. Preparing for Industry 4.0 and Digital Transformations In S.M.E.s. European and National Aspects. Godishnik na U.N.S.S., 1, pp.191-207.

[30] Müller, J.M., Buliga, O. and Voigt, K.I., 2018. Fortune favors the prepared: How S.M.E.s approach business model innovations in Industry 4.0. Technological Forecasting and Social Change, 132, pp.2-17.

[31] Nair, J., Chellasamy, A. and Singh, B.B., 2019. Readiness factors for information technology adoption in S.M.E.s: testing an exploratory model in an Indian context. Journal of Asia Business Studies.

[32] Piccarozzi, M., Aquilani, B. and Gatti, C., 2018. I4.0 in management studies: A systematic literature review. Sustainability, 10(10), p.3821.

[33] Pirola, F., Cimini, C. and Pinto, R., 2019. Digital readiness assessment of Italian S.M.E.s: A casestudy research. Journal of Manufacturing Technology Management.

[34] Rajnai, Z. and Kocsis, I., 2017, September. Labor market risks of I4.0, digitization, robots and A.I. In 2017 IEEE 15th International Symposium on Intelligent Systems and Informatics (S.I.S.Y.) (pp. 000343-000346). IEEE

[35] Raj, A., Dwivedi, G., Sharma, A., de Sousa Jabbour, A.B.L. and Rajak, S., 2020. Barriers to the adoption of industry 4.0 technologies in the manufacturing sector: An inter-country comparative perspective. International Journal of Production Economics, 224, p.107546.

[36] Safar, L., Sopko, J., Bednar, S. and Poklemba, R., 2018. Concept of S.M.E. business model for industry 4.0 environment. T.E.M. Journal, 7(3), p.626.

[37] Saturno, M., Ramos, L.F.P., Polato, F., Deschamps, F. and Loures, E.D.F.R., 2017. Evaluation of interoperability between automation systems using multi-criteria methods. Procedia manufacturing, 11, pp.1837-1845.

[38] Sommer, L., 2015. Industrial revolution-industry 4.0: Are German manufacturing S.M.E.s the first victims of this revolution?. Journal of Industrial Engineering and Management, 8(5), pp.15121532.

[39] Stentoft, J. and Rajkumar, C., 2020. The relevance of Industry 4.0 and its relationship with moving manufacturing out, back and staying at home. International Journal of Production Research, 58(10), pp.2953-2973.

[40] Stentoft, J., Jensen, K.W., Philipsen, K. and Haug, A., 2019, January. Drivers and barriers for Industry 4.0 readiness and practice: a S.M.E. perspective with empirical evidence. In Proceedings of the 52nd Hawaii International Conference on System Sciences. 
[41] Stock, T., Obenaus, M., Kunz, S. and Kohl, H., 2018. Industry 4.0 as enabler for a sustainable development: A qualitative assessment of its ecological and social potential. Process Safety and Environmental Protection, 118, pp.254-267.

[42] Trstenjak, M., Lisjak, D., Opetuk, T. and Pavković, D., 2019, July. Application of multi criteria decision making methods for readiness factor calculation. In IEEE EUROCON 2019-18th International Conference on Smart Technologies (pp. 1-6). IEEE.

[43] Tupa, J., Simota, J. and Steiner, F., 2017. Aspects of risk management implementation for I4.0. Procedia Manufacturing, 11, pp.1223-1230.

[44] Truvé, T., Wallin, M. and Ryfors, D., 2019. Swedish manufacturing S.M.E.s readiness for Industry 4.0: What factors influence an implementation of Artificial Intelligence and how ready are manufacturing S.M.E.s in Sweden?.

[45] Vaidya, S., Ambad, P. and Bhosle, S., 2018. Industry $\quad 4.0-\mathrm{a} \quad$ glimpse. Procedia Manufacturing, 20, pp.233-238.

[46] Widayani, A., Astuti, E.S. and Saifi, M., 2020, May. Competence and readiness of small and medium industries against of industrial revolution 4.0. In I.O.P. Conference Series: Earth and Environmental Science (Vol. 485, No. 1, p. 012114). IOP Publishing.

[47] Young, R. and Jordan, E., 2008. Top management support: Mantra or necessity?. International journal of project management, 26(7), pp.713725. 